\title{
Familial Takayasu arteritis - a pediatric case and a review of the literature
}

\author{
Kimberly A Morishita ${ }^{1 *}$, Karen Rosendahl ${ }^{2}$, Paul A Brogan ${ }^{3}$
}

\begin{abstract}
Takayasu arteritis (TA) is a rare chronic inflammatory disease of the aorta and its major branches. It is seen predominantly in females during the second and third decades of life, although it can occur in childhood. The aetiology of TA remains unknown. To date, familial cases of TA have been considered rare; however, a review of the literature suggests that cases are accumulating. We report a case of two sisters affected by severe TA, and review other reported familial cases.
\end{abstract}

\section{Background}

Takayasu arteritis (TA) is a chronic, idiopathic large vessel vasculitis. It primarily involves the aorta and its main branches. Although the aetiology of TA has been extensively investigated, it remains unknown. The disease is more common in females and is seen predominantly in Asian countries although it has a worldwide distribution. Despite several reported associations with HLA alleles, results are heterogeneous and differ across populations. A review of the literature suggests that familial TA may not be as rare as once thought and this finding may have both aetiological and clinical implications for family screening. The following case describes a 4-year old girl with severe TA whose older sister died of the same disease.

\section{Case}

Our female patient was born to non-consanguineous Italian parents in 1990 after an uneventful pregnancy. Both parents were healthy and the family history was unremarkable except for the following history in her sibling. Her older sister had been diagnosed with TA in Belgium at the age of 10 years. Only limited information was available to us regarding this sibling: she had a history of severe hypertension and persistently elevated acute phase markers (high erythrocyte sedimentation rate, ESR; and high C-reactive protein, CRP) as well as involvement of her cerebral, abdominal, and renal arteries. At the age of 15 years this sibling died of a massive cerebral

\footnotetext{
*Correspondence: kmorishita@cw.bc.ca

'Division of Rheumatology, Department of Pediatrics, British Columbia's

Children's Hospital, University of British Columbia, Vancouver, BC, Canada

Full list of author information is available at the end of the article
}

haemorrhage. No autopsy was performed; therefore, the cause of the haemorrhage was never identified. Our patient was transferred to Great Ormond Street Hospital (GOSH), London in 2006 after a severe and resistant course. She had been diagnosed with TA at the age of 4 years after presenting with hypertension and persistently raised inflammatory markers (ESR 50-105 mm/hour; CRP $40-95 \mathrm{mg} / \mathrm{L}$ ). Catheter arteriography at the time of diagnosis revealed stenotic abnormalities of the superior mesenteric, renal and internal carotid arteries. Her initial management included prednisone, nifedipine, and labetolol. Over the next several years she developed impaired renal function with glomerular filtration rates between 50 $60 \mathrm{ml} / \mathrm{min} / 1.73 \mathrm{~m}^{2}$ and had ongoing hypertension despite addition of enalapril and commencement on azathioprine. In 2002, at the age of 12 years she underwent bilateral balloon dilatation of her renal arteries. In 2004 she had three intracranial haemorrhages from a basilar artery aneurysm, which was subsequently coiled. Between 2003 and 2006 she developed recurrent gastrointestinal complaints of abdominal pain, diarrhoea and weight loss due to superior mesenteric artery (SMA) stenosis and secondary intestinal ischemia. She required balloon dilatation of the SMA on four separate occasions. During the same time period she was diagnosed with episodic atrial fibrillation requiring treatment with flecainide. Her echocardiogram showed bilateral ventricular hypertrophy, mild aortic regurgitation, and mild stenosis of the distal main pulmonary artery. The atrial fibrillation and cardiac changes were felt to be secondary to longstanding hypertension in the context of large vessel vasculitis. Acetylsalicylic acid (ASA) or other antiplatelet agent was not initiated due to the patient's
Ciomed Central

() 2011 Morishita et al; licensee BioMed Central Ltd. This is an Open Access article distributed under the terms of the Creative Commons Attribution License (http://creativecommons.org/licenses/by/2.0), which permits unrestricted use, distribution, and reproduction in any medium, provided the original work is properly cited. 
previous history of intracranial bleeds, precarious vasculature, and persisting hypertension.

At 16 years of age (in 2006) she was transferred to GOSH for a second opinion. She had severe hypertension (systolic blood pressure on average $230 \mathrm{mmHg}$ ), severe failure to thrive (weight $21 \mathrm{~kg}$; height $129 \mathrm{~cm}$, both significantly below the $3^{\text {rd }}$ percentile; body mass index $12.6 \mathrm{~kg} / \mathrm{m}^{2}$ ), chronic renal failure (glomerular filtration rate $52 \mathrm{ml} / \mathrm{min} / 1.73 \mathrm{~m}^{2}$ ), chronic diarrhoea and intestinal malabsorption from ischaemia, and osteoporosis with vertebral compression fractures. She largely used a wheelchair and could only walk approximately 50 metres, mobility mainly limited by general weakness and musculoskeletal debilitation. Physical examination revealed a pale, pre-pubertal girl. She had loud bilateral carotid artery bruits, a left renal artery bruit and otherwise normal peripheral pulses. The ESR was persistently elevated (70 mm/hour) and she had mild anaemia of chronic disease (haemoglobin $9.8 \mathrm{~g} / \mathrm{dL}$ ). Catheter digital subtraction arteriography (DSA) and magnetic resonance angiography (MRA) findings revealed widespread arterial pathology, which combined with the ongoing chronic inflammation (in the absence of other identified causes) was consistent with TA (Figure 1). Between 2006 and 2007 the patient's clinical status remained stable on moderate doses of oral prednisone $(0.5 \mathrm{mg} / \mathrm{kg} /$ day), azathioprine $2 \mathrm{mg} / \mathrm{kg} /$ day, and multiple antihypertensive medications, although the ESR remained persistently elevated (ranging from 30-80 mm/hour over several measurements months apart). Pamidronate infusions for osteoporosis were given monthly. In 2007, she developed pain and stiffness in both hips and an MRI confirmed the presence of bilateral hip joint effusions with thickened synovium as well as significant synovial enhancement. Due to presumed hip synovitis azathioprine was switched to subcutaneous methotrexate $\left(15 \mathrm{mg} / \mathrm{m}^{2}\right.$ weekly). Despite attempts to lower her baseline prednisone dose, she could not be weaned below $0.5 \mathrm{mg} / \mathrm{kg} / \mathrm{day}$. The patient initially declined anti-tumor necrosis factor (TNF) alpha therapy (because of numerous concerns including needle phobia), although at the age of 17 years adalimumab $20 \mathrm{mg}$ subcutaneous fortnightly was added to her treatment in an attempt to spare her baseline corticosteroid dose [1]. This resulted in normalisation of the ESR within receiving 2 doses after which the patient refused to continue with this treatment because of pain associated with the injections. At the time of writing she has been transitioned to adult care and remains on prednisone and methotrexate, in addition to multiple anti-hypertensive agents. Ongoing palliative care of symptoms is now the primary therapeutic goal.

\section{Discussion}

Individual case reports of familial TA consistently refer to the rarity of this condition. We reviewed the literature and found 30 other reports, the majority of which were from Japan (Table 1) [2-16]. An extensive amount of research has focussed on HLA associations. Although some consistent HLA associations have been identified with HLA- A10, B5, Bw52, DR2, DR4, B21 and B22 [17-22], many of these remain unconfirmed and variable across different ethnic groups. A recent report of a multiplex family with TA raised the question of whether there could be an autosomal recessive form of the disease [5]. We concur with the authors who propose the use of homozygosity mapping in these cases. Homozygosity mapping may enable us to identify candidate genes involved in the pathogenesis of TA, particularly in consanguineous families [23], and could ultimately provide insight into non-familial TA.

Our literature search revealed that a large proportion of familial cases were reported over 15 years ago. The reason for this is unclear. The availability and quality of

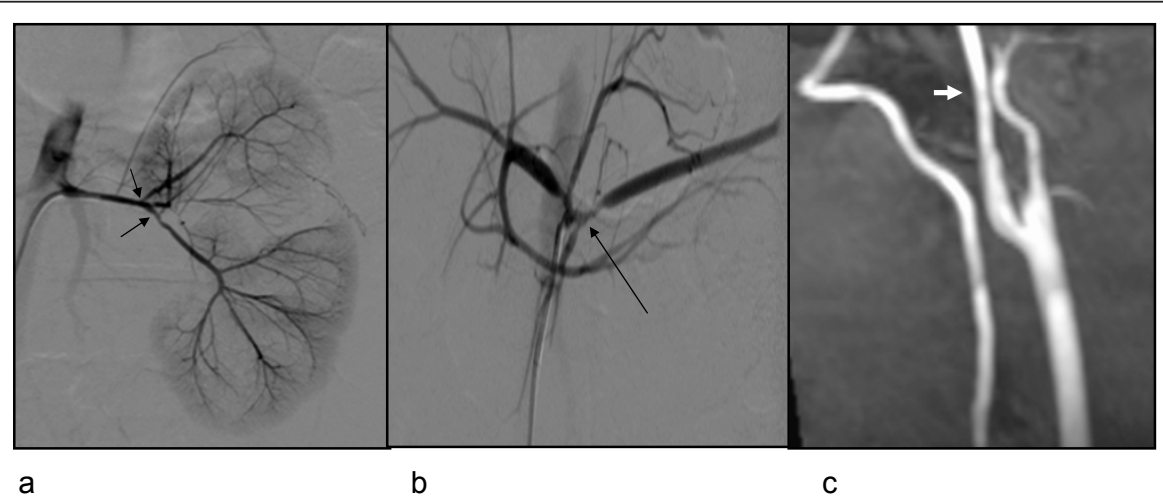

Figure 1 Angiogram from 14.09.2006, showing a) narrowed renal arteries, and severe stenoses of their main intrarenal braches (arrows), b) celiac trunk and its main branches are stenosed at its trifurcation (arrow) c) magnetic resonance angiography from 10.11.2006 showing smooth narrowing of the proximal right internal carotid artery 
Table 1 Summary of familial cases of Takayasu arteritis

\begin{tabular}{|c|c|c|c|c|}
\hline Case & Affected family members & Country & Possible genetic associations & Reference \\
\hline 1 & Monozygotic twins & Japan & HLA A11, Bw40, Bw52 & [4] \\
\hline 2 & & Japan & HLA A9, A10 & [3] \\
\hline 3 & & Japan & HLA Aw31-Bw52 & * \\
\hline 4 & Sisters & Japan & - & [13] \\
\hline 5 & & Europe & - & [6] \\
\hline 6 & & Japan & - & * \\
\hline 7 & & Japan & HLA Aw24-Bw52 & * \\
\hline 8 & & Japan & HLA Aw24-Bw52 & * \\
\hline 9 & & Japan & HLA Aw24-Bw40 & * \\
\hline 10 & & Japan & HLA Aw24-Bw52-DR2-MT1 & * \\
\hline 11 & & India & - & [7] \\
\hline 12 & & Europe & - & [11] \\
\hline 13 & & Taiwan & HLA DR4 & [8] \\
\hline 14 & & India & HLA B5 & [9] \\
\hline 15 & & Europe & - & present case \\
\hline 16 & Brothers & Europe & - & [14] \\
\hline 17 & & Japan & HLA A9, DRw4 & [15] \\
\hline 18 & & Japan & HLA DR2, DR4 & [12] \\
\hline 19 & Brother and sister & Japan & HLA Aw24-Bw52 & * \\
\hline 20 & & Japan & HLA Aw24-Bw52-Dw12 & * \\
\hline 21 & Mother and daughter & Japan & - & + \\
\hline 22 & & Japan & HLA Bw52-DR2 & * \\
\hline 23 & & Japan & - & + \\
\hline 24 & & Japan & HLA Aw19-Bw52-Dw12 & * \\
\hline 25 & & Japan & - & [10] \\
\hline 26 & Aunt and niece & Japan & - & * \\
\hline 27 & & Japan & - & * \\
\hline 28 & & Japan & HLA Aw24-Bw52-DR2-MTI & * \\
\hline 29 & & Korea & - & [16] \\
\hline 30 & Cousins & Japan & HLA Bw52 & * \\
\hline 31 & Multiple siblings & Pakistan & - & {$[5]$} \\
\hline
\end{tabular}

* Cited in reference [2].

${ }^{+}$Cited in reference [3].

- Genetic testing not performed or no association reported.

imaging modalities used in the past may have affected diagnostic accuracy; however, for those cases in which clinical details were provided, many cases had angiographic findings typical of TA suggesting that the diagnoses were reliable $(3,8,9,12,15)$. Most of the older studies originated in Japan, and it is possible that even if new cases are occurring, they are simply not being reported unless they are unique in some way.

Our review of familial cases also revealed that many affected siblings were only diagnosed after they presented with late signs and symptoms of disease, without having previously been evaluated for absent pulses, four-limb blood pressure inequality, or hypertension $[8,9,15]$. This was especially true for non-twin cases. Tsai and colleagues report a case of two teenage sisters in which there was a significant delay in diagnosis of the second sister in part due to failure to palpate pulses and obtain 4-limb blood pressures at the time of initial evaluation [8]. An asymmetric radial pulse was noted incidentally on follow-up examination after a two month history of fever of unknown origin and vague left arm pain, even though the patient's older sister had previously been diagnosed with TA. Makino and colleagues report a case of two brothers aged 17 and 14 years, where the younger brother was diagnosed 4 years after the older brother when he presented with neck pain and general malaise. Physical examination revealed blood pressures of 144/60 and 160/54 mmHg in the right and left arms, respectively. Arteriography showed a grossly dilated aortic arch and bilateral carotid artery narrowing [15]. Other cases are similarly described with delayed diagnosis of familial TA with considerable late disease related damage and large vessel injury [12]. 
The diagnosis of TA is not always straightforward and is based on angiographic abnormalities of the aorta or its major branches along with other clinical or laboratory features to support the diagnosis of a systemic vasculitis. The differential diagnosis for TA is broad and is summarized in Table 2. Although the pattern of vessel involvement of both siblings reported in this case was somewhat atypical, the most likely diagnosis was felt to be TA given the constellation of clinical, laboratory, and radiologic findings demonstrating arterial lesions affecting major branches of the aorta. It is entirely possible, however, that these two siblings and perhaps some of the cases reported in the literature actually represent an as yet undefined and unusual genetic inflammatory vasculopathy mimicking TA. We suggest that detailed genetic study of such informative families using new genetic technologies such as homozygosity mapping followed by second generation resequencing of areas of homozygosity could reveal novel genetic causes of unusual familial large vessel vasculitis of this nature.

\section{Conclusion}

Familial TA is an important clinical entity, which may not be as rare as we once thought. This case and review provides further support for the role of as yet undefined genetic factors in the development of TA, and emphasizes the need for studying such informative familial cases to look for candidate genes. In addition, physicians

Table 2 Differential diagnosis for Takayasu arteritis

\begin{tabular}{ll}
\hline Infections & Septicemia or endocarditis (mycotic \\
aneurysms) & Tuberculosis \\
& Syphilis \\
& Human immunodeficiency virus \\
& Borelliosis \\
& Brucellosis \\
\hline Inflammatory vasculitides & Giant cell arteritis (adults) \\
& Kawasaki disease \\
& Polyarteritis nodosa \\
& Wegener's granulomatosis \\
\hline Autoimmune conditions & Systemic lupus erythematosus \\
& Rheumatic fever \\
& Sarcoidosis \\
\hline Non-inflammatory & Fibromuscular dysplasia \\
vasculopathies & William's syndrome \\
& Congenital coarctation of the aorta \\
& Congenital mid-aortic syndrome \\
& Ehlers-Danlos type IV \\
Marfan syndrome & Neurofibromatosis type I \\
\hline Other & Post radiation therapy \\
\hline
\end{tabular}

should maintain a high index of suspicion for the possibility of TA in the siblings or other family members of affected patients. Screening using four-limb blood pressure measurements and pulse checks should be considered in these cases, progressing to non-invasive imaging such as ultrasound followed by MRA if abnormalities are detected. Such relatively non-invasive screening may prevent delays in diagnosis and minimize morbidity of other familial cases.

\section{Consent}

Written consent was obtained from the patient's mother for this publication.

\section{Acknowledgements}

We thank Lil-Sofie Muller, MD, Great Ormond Street Hospital, London, UK for further review of the radiological data.

\section{Author details}

'Division of Rheumatology, Department of Pediatrics, British Columbia's Children's Hospital, University of British Columbia, Vancouver, BC, Canada. ${ }^{2}$ Department of Radiology, Institute of Child Health and Great Ormond St Hospital for Children, London, UK. ${ }^{3}$ Department of Rheumatology, Institute of Child Health and Great Ormond St Hospital for Children, London, UK.

\section{Authors' contributions}

KM and PB wrote the initial manuscript draft. KR performed the analysis and interpretation of radiological data. All authors critically reviewed and revised drafts. All authors read and approved the final manuscript.

\section{Competing interests}

The authors declare that they have no competing interests.

Received: 21 September 2010 Accepted: 2 February 2011

Published: 2 February 2011

\section{References}

1. Hoffman GS, Merkel PA, Brasington RD, Lenschow DJ, Liang P: Anti-tumor necrosis factor therapy in patients with difficult to treat Takayasu arteritis. Arthritis Rheum 2004, 50:2296-304.

2. Numano F: Hereditary factors of Takayasu arteritis. Heart Vessels Suppl 1992, 7:68-72.

3. Enomoto S, Iwasaki Y, Bannai S, Nara Y, Matsuoka A, Aizawa Y, Shibata A: Takayasu's disease in twin sisters. Jpn Heart J 1984, 25:147-52

4. Numano F, Isohisa I, Kishi U, Arita M, Maezawa H: Takayasu's disease in twin sisters. Possible genetic factors. Circulation 1978, 58:173-7.

5. Jeeva I, Sajid J, Ali O, Bonthron DT, Frossard PM: Atypical Takayasu arteritis: a family with five affected siblings. Med Sci Monit 2007, 13:101-5.

6. Hermann VB, Pluhor J: Beiträge zur Pathogenese des AortenbogenSyndromes. Zschr Inn Med 1964, 10:453.

7. Tyagi S, Reddy NK, Khalilullah M: Familial occurrence of non-specific aortoarteritis in two sisters. Indian Heart J 1991, 43:193-4.

8. Tsai MJ, Lin SC, Wang JK, Chou CC, Chiang BL: A patient with familial Takayasu's arteritis presenting with fever of unknown origin. J Formos Med Assoc 1998, 97:351-3.

9. Naik N, Kohari SS, Sharma S: Familial Takayasu's aortoarteritis in two sisters. Indian Heart J 1999, 51:75-6.

10. Valentini F, Di Folca A: Takayasu's disease. A review of the literature. A study of a familial case of Takayasu's arteritis and the possible associations with type-1 diabetes mellitus. Minerva Med 1989, 80:1351-8.

11. Khaidarov BM, Mansurkhodzhaeva NT, Timoshenkova El: Takayasu syndrome in 2 sisters. Pediatriia 1991, 1:94-5.

12. Kodama K, Kida O, Morotomi Y, Tanaka K: Male siblings with Takayasu's arteritis suggests genetic etiology. Heart Vessels 1986, 2:51-54.

13. Hirsch MS, Aikat BK, Basu AK: Takayasu's arteritis: report of five cases with immunologic studies. Bull Johns Hopkins Hosp 1964, 115:29-64. 
14. Zyrianov BN, Klimenko AG, Tsimbaliuk VP: Takayasu syndrome in brothers. Kardiologiia 1968, 8:130-2.

15. Makino N, Senda Y, Yamaguchi Y: Takayasu's disease in two brothers. Analysis of HLA types. Br Heart J 1981, 46:446-8.

16. Hong CY, Yun YS, Choi JY, Sul JH, Lee KS, Cha SH, Hong YM, Lee HJ, Hong YJ, Sohn KC: Takayasu arteritis in Korean children: clinical report of seventy cases. Heart Vessels Suppl 1992, 7:91-6.

17. Mehra NK, Jaini R: Immunogenetics of peripheral arteriopathies. Clin Hemorheol Microcirc 2000, 23:225-32.

18. Dong RP, Kimur A, Numenno F, Nashimura Y, Sasazuki T: HLA linked susceptibility and resistance to Takayasu arteritis. Heart Vessels Suppl 1992, 7:73-80.

19. Kasuya $K$, Hashimoto $Y$, Numenno F: Left ventricular dysfunction and HLA Bw52 antigen in Takayasu arteritis. Heart Vessels Suppl 1992, 7:116-9.

20. Khraishi MM, Gladman DD, Dagenais P, Fam AG, Keystone EC: HLA antigens in North American patients with Takayasu arteritis. Arthritis Rheum 1992, 35:573-575.

21. Mehra NK, Jaini R, Baramurugan A, Kanga U, Prabhakaran D, Jain S, Talwar KK, Sharma BK: Immunogenetic analysis of Takayasu arteritis in Indian patients. Int J Cardiol 1998, 66:S127-132.

22. Gulati A, Bagga A: Large vessel vasculitis. Pediatr Nephrol 2010, 25:1037-1048.

23. Nalls MA, Guerreiro RJ, Simon-Sanchez J, Bras JT, Traynor BJ, Gibbs JR, Launer L, Hardy J, Singleton AB: Extended tracts of homozygosity identify novel candidate genes associated with late-onset Alzheimer's disease. Neurogenetics 2009, 10:183-90.

\section{doi:10.1186/1546-0096-9-6}

Cite this article as: Morishita et al: Familial Takayasu arteritis - a pediatric case and a review of the literature. Pediatric Rheumatology 2011 9:6.

\section{Submit your next manuscript to BioMed Central and take full advantage of:}

- Convenient online submission

- Thorough peer review

- No space constraints or color figure charges

- Immediate publication on acceptance

- Inclusion in PubMed, CAS, Scopus and Google Scholar

- Research which is freely available for redistribution

Submit your manuscript at www.biomedcentral.com/submit 